\title{
Educação de jovens e adultos: artes visuais e trabalho no contexto escolar e extraescolar amazônico
}

\section{Youth and adult education: visual arts and labor in the Amazonian school and extra-curricular context}

\author{
Thiago da Silva Rodrigues \\ Universidade Federal do Pará - UFPA \\ Doriedson do Socorro Rodrigues \\ Universidade Federal do Pará - UFPA
}

\section{RESUMO}

Este trabalho é resultado de uma experiência didático-pedagógica com os alunos da EJA durante a $4^{a}$ etapa no exercício do ensino e aprendizagem das artes em uma escola de Santarém-PA. O estudo toma o trabalho artesanal das cuias ligado às mulheres da Associação das Artesãs Ribeirinhas de Santarém (ASARISAN) como objeto de análise e aprendizagem, à luz de ideias de Vázquez (2011) e Marx (2008), dentre outros, no campo do trabalho e dos PCNs (1998) para o ensino das artes. Apresentamos, em termos conclusivos, possibilidades de um ensino prático das artes visuais no contexto de trabalho em que se dão as produções das artesãs da ASARISAN, além de considerar as relações existentes entre arte e trabalho no cenário amazônico como elementos de conhecimento, identidade, cultura e perspectivas de transformação para a vida dos alunos.

Palavras-chave: educação de jovens e adultos, artes visuais, trabalho, cuias.

\begin{abstract}
This work is the result of a didactic-pedagogical experience with students from YAE during the $4^{\text {th }}$ stage of Teaching and Learning of Arts at a school in Santarém-PA. The study concerns the handcrafted work of "cuias" by artisan ladies from Association of Riverine Women of Santarém-PA (ASARISAN) as object of analysis and learning under the light of Vázquez (2011)'s and Marx (2008)'s ideas, among others in the field of labor, and PCNs (1998) related to the teaching of arts. Here we show, in conclusive terms, the possibilities of a practical learning process in visual arts inside the work context in which the ASARISAN artisans' production happens, besides considering the relationships between art and labor in the Amazonian scene as elements of knowledge, identity, culture and perspectives of transformation in the students' lives.
\end{abstract}

Keywords: Youth and Adult Education. Visual Arts. Work. Cuia

Revista Digital do LAV - Santa Maria - vol. 8, n. 3, p. 48 - 72. - set./dez. 2015 ISSN 1983 - 7348 


\section{INTRODUÇÃO}

Neste trabalho apresentamos análises sobre uma experiência didáticopedagógica quanto ao ensino de artes visuais junto à Educação de Jovens e Adultos, a partir de um contexto escolar e extraescolar amazônico, tomando-se a Escola Municipal de Ensino Fundamental Nazaré Demétrio Mussi, localizada no Bairro do Mararu, cidade de Santarém-Pará, situada bem a Oeste e com mais de 290 mil habitantes (Censo IBGE, 2010), como locus de trabalho.

A escola Nazaré Demétrio Mussi fica localizada a 15 minutos de ônibus do centro urbano de Santarém. Quando atuamos como docentes nessa Escola no período de fevereiro a julho de 2013, observamos que, nesse locus de pesquisa, 26 alunos frequentavam a Educação de Jovens e Adultos 4a etapa, com faixa etária entre 17 e 23 anos, caracterizando-se em sua maioria pela repetência nos anos regulares, impulsionando a escola a formar uma turma nessa modalidade.

A partir de breve avaliação diagnóstica, resultante de pesquisa de campo decorrente do exercício do magistério ali desenvolvido, constatamos pouca motivação para a disciplina artes e para os próprios estudos de maneira geral, observando as expectativas da classe para os estudos da arte enquanto disciplina. Era preciso, então, mesmo diante do desafio do ensino das artes no contexto sócio-cultural-econômico e afetivo dessa escola, encontrar saídas que desembocassem em perspectivas de ensino e aprendizagem que considerassem a realidade dos alunos tanto no universo escolar como no universo extraescolar, no sentido de favorecer a compreensão das artes como elemento de identidade e trabalho. Roriz (2010, p. 69), em uma exposição do artesanato pelo Brasil, diz que não se pode entender esta arte apenas como "um conjunto de técnicas e processos dirigidos à produção de bens manufaturados", mas é preciso relacionar este fato ao contexto cultural do artesão para não se ter como consequência "a perda de identidade e cultura autêntica". A despeito desta última, Brandão (2002, p. 16) afirma que cultura é

uma palavra universal, mas um conceito cientifico nem sempre aceito por todos os que tentam decifrar o que os seus processo e conteúdos querem significar, e que misteriosamente existe tanto fora de nós, em qualquer dia de nosso cotidiano, quanto dentro de nós, seres obrigados a apender, desde criança e pela vida toda afora, a compreender as suas várias gramáticas e a 'falar' as suas várias linguagens.

Revista Digital do LAV - Santa Maria - vol. 8, n. 3, p. 48 - 72. - set./dez. 2015 ISSN 1983 - 7348 http://dx.doi.org/10.5902/1983734820532 
Diante também do desafio de se agregar a arte ao seu aspecto cultural, propusemo-nos a trabalhar o ensino e a aprendizagem das artes a partir da realidade do trabalho artesanal santareno desenvolvido por uma comunidade de artesãs, buscando articular os conhecimentos escolares ${ }^{1}$ aos saberes culturais da comunidade, tomando o trabalho com cuias ${ }^{2}$ artesanais desenvolvido pela Associação das Artesãs Ribeirinha de Santarém (ASARISAN), na região do Aritapera. As cuias e demais peças aí produzidas, além de elemento símbolo da culinária paraense, constituem o universo das artes visuais à medida que atendem padrões estéticos que revelam a cultura de um povo e são objetos de apreciação.

Para os propósitos deste trabalho, tomamos a diferença entre saber e conhecimento delineada por Zaidan (2003), para a qual, apoiada em Fiorientini, Souza e Melo (1988), conhecimento estaria ligado ao resultado de produção científica, oriundo de pesquisas, enquanto que saber seria um modo de conhecer-saber menos rigoroso, mais relacionado à esfera da praticidade. Assim, conhecimento estaria atrelado ao científico e saber ao senso comum. Apoiada em Barth (1993), o saber seria algo provisório, evolutivo e cultural, "[...] porque pessoal/relacional/contextual, podendo modificar-se com o tempo e a experiência $[\ldots]$ " (p. 87), sendo efetivo "[...] porque relaciona-se com os sujeitos, a construção dos sujeitos, suas auto-imagens, julgamentos, sentimentos" (p. 87). Com base em Bernard Charlot (2000), destaca Zaidan (2003) que o saber é fruto de relações.

Em temos pedagógicos, registre-se que nossa intenção inicial era apenas proporcionar aos alunos uma experiência prática para se ter conhecimento dos processos anteriores que perpassam o objeto artístico antes de chegar ao produto final, de modo que, após vivenciar todas as etapas de produção das cuias artesanais, seria garantida uma valorização da arte local, além de contribuir para o fato de que o

aluno desenvolve sua cultura de arte fazendo, conhecendo e apreciando produções artísticas, que são ações que integram o perceber, o pensar, o aprender, o recordar, o imaginar, o sentir, o expressar, o comunicar. (PCN, 1998, p. 19).

\footnotetext{
${ }^{1}$ Segundo Lopes (1999, p. 26), "[...] na definição do conhecimento escolar: 1) trata-se de um conhecimento selecionado a partir de uma cultura social mais ampla, que passa por um processo de transposição didática, ao mesmo tempo que é disciplinarizado; 2) constitui-se no embate com os demais saberes sociais, diferenciando-se dos mesmos. Em síntese, o conhecimento escolar define-se em relação aos demais saberes sociais, ou seja o conhecimento científico, o conhecimento cotidiano ou os saberes populares".

${ }^{2} \mathrm{Na}$ definição do Dicionário da Língua Portuguesa, de Evanildo Bechara (2011): 1 Fruto da cuieira, com casca de forma oval. 2 Vasilha feita da casca desse fruto maduro e cortado ao meio. 3 Qualquer vasilha com essa forma.
}

Revista Digital do LAV - Santa Maria - vol. 8, n. 3, p. 48 - 72. - set./dez. 2015 ISSN 1983 - 7348 
Entretanto, à medida que o projeto ganhava corpo ao longo do semestre e entendendo melhor a cada dia as necessidades imediatas dos alunos que precisavam trabalhar para ajudar no orçamento familiar ou mesmo para o sustento dos filhos já que algumas alunas eram mães, passamos a compreender que o conhecer e o valorizar simplesmente a produção cultural local não eram mais suficientes a ponto de inspirar os discentes para as artes e nem para um futuro promissor quanto ao uso dos saberes culturais locais no processo de ensino e aprendizagem e de compreensão da realidade que envolve o homem.

Era preciso, para além das intenções iniciais, perceber o elemento trabalho, não considerado como objeto de análise anteriormente, como etapa muito importante à formação dos alunos e compreender a arte a partir de seu uso mercadológico, assumindose uma posição crítica diante da realidade, tal qual o exposto por Semeraro (2006, p. 19):

é necessário aprender a criar uma capacidade crítica frente ao saber acumulado e repassado oficialmente, que deve ser visto não como óbvio e natural, mas como sendo interpretado e administrado por grupos sociais que visam precisos objetivos políticos.

Não obstante, essa posição pedagógica possibilitou ainda mais trabalhar as artes como elemento de identidade e trabalho a partir da relação do aprendiz com o mundo do trabalho artístico. Estar em sala de aula e apenas conhecer teoricamente o que se passa no próprio ambiente de criação da arte é uma realidade muito presente no ensino das artes. Roriz (2010, p. 12) afirma que os "jovens podem ter interesse em qualquer um ofício artesanal, mas devidos aos obstáculos à concretização desse interesse em algo que lhes gere uma renda satisfatória, acabam abrindo mão da produção cultural, para de dedicarem a outras atividades." A escola pode ter esse papel que media o ensino aliado a um contexto real, prática esta vivida pelos alunos da EJA em que presenciaram de perto o trabalho artístico e suas interfaces econômicas e culturais.

Isto posto, neste escrito assumimos que, no trabalho pedagógico com as artes, a partir da experiência formativa presente na comunidade por nós observada, há necessidade de os jovens da Educação de Jovens e Adultos (EJA) compreenderem o elemento artístico enquanto trabalho ${ }^{3}$ realizado pelo homem, resultante tanto da vivência no cotidiano que potencializa elementos culturais como objetos de ensino e de

\footnotetext{
${ }^{3}$ Para Marx (2008, p. 297): "Antes de tudo o trabalho é um processo entre o homem e a Natureza, um processo em que o homem, por sua própria ação, media, regula e controla seu metabolismo com a Natureza (...) a fim de apropriar-se da matéria natural numa forma útil para sua própria vida." Além disso, o trabalho aproxima os homens que constroem, produzem as artes, reúnem-se em associações, religiões, enfim, constrói a imagem do próprio homem.
}

Revista Digital do LAV - Santa Maria - vol. 8, n. 3, p. 48 - 72. - set./dez. 2015 ISSN 1983 - 7348 http://dx.doi.org/10.5902/1983734820532 
aprendizagem, mas também elemento que Ihes garantem a própria existência, a partir das relações de mercado que se estabelecem entre os homens e a natureza, por meio do trabalho.

Apresentamos inicialmente uma breve descrição do entrelace da arte e do trabalho na construção da história do homem. Adiante, uma visão da arte enquanto processo metodológico de ensino busca revelar as dificuldades recorrentes de sala de aula ocasionadas por um componente curricular ainda em construção. Na terceira seção, apresentamos descrições das etapas da oficina ministrada pelas artesãs e fotografias que garantem uma maior visualização e entendimento do trabalho realizado. Uma entrevista feita com as artesãs permite entender com mais afinco sobre a forma como arte e trabalho se cruzam dentro do contexto ribeirinho. Dentro das considerações finais existe um resgate ou mesmo um outro olhar a respeito de situações que por ventura não foram mencionadas anteriormente e que reforçam a importância de se promover ações extraescolares juntamente aos alunos de EJA com o intuito de fornecer pistas e apontar caminhos que revelem a arte por meio do trabalho e o trabalho por meio da arte.

\section{ARTE E TRABALHO: PROCESSOS DE PRODUÇÃO HUMANA EM UNIDADE}

Arte e trabalho estão relacionados desde muito tempo. Segundo Proença (2012), havemos de considerar, num período dito pré-histórico, o trabalho como produtor do atendimento das necessidades básicas do homem para comer e se proteger, provocando a criação de ferramentas rústicas destinadas à caça como o machado de pedra do período paleolítico. Nesse mesmo período, o homem também confeccionou objetos para atender as necessidades ligadas ao mundo das subjetivações em relação ao que o cercava, daí os registros, ou quer em virtude da necessidade de produzir objetos objetivando o caráter utilitário de seus afazeres domésticos, ou da necessidade de se expressar diante do mundo como com suas pinturas e gravações rupestres.

Já na modernidade segundo Farthing (2011), há uma grande mudança no conceito de arte que passa a considerar a fotografia e o cinema, havendo uma ruptura com o passado e os artistas modernos são responsáveis por obras distantes dos formatos tradicionais. "Pintores, escritores e escultores rejeitaram as formas da arte e literatura 'tradicionais' e saíram em busca de novos modos de representar o mundo industrializado fragmentado ao seu redor" (p. 444). Essa busca por novas formas de se expressar representa a mudança no conceito de arte.

Revista Digital do LAV - Santa Maria - vol. 8, n. 3, p. 48 - 72. - set./dez. 2015 ISSN 1983 - 7348 http://dx.doi.org/10.5902/1983734820532 
O trabalho é a categoria que nos constitui o ser social, o humano que somos, produzindo-nos enquanto sujeitos históricos e também como produtores de saberes, de produtos, tal qual o que realizam as artesãs da Associação por nós observada quanto à experiência de ensino e de aprendizagem das artes junto a estudantes da EJA. No dizer de Saviani (1995, p. 12).

Em outros termos, se os animais em geral se adaptam a natureza, o homem tem que fazer o contrário, ele tem que adaptar a natureza a si, ele tem que agir sobre a natureza transformando-a, se ele não fizer isso ele perece, [ou seja,] ele não subsiste enquanto homem e este ato de transformar a natureza é exatamente o que se conhece pelo nome de trabalho.

Destacamos que para os propósitos da presente exposição, tomamos a categoria trabalho na perspectiva marxista, entendendo que é por meio do trabalho que o homem se emancipa, constrói-se, humaniza-se, transforma a natureza e as suas relações, objetivando sua realização. Tomamos então o trabalho como marca humana de humanização, pressupondo a satisfação das necessidades do homem por meio dele, agindo e reagindo a partir da natureza e dos outros homens, projetando e materializando o novo, como o faz por meio dele com a construção das artes.

Pressupomos o trabalho sob forma exclusivamente humana. Uma aranha executa operações semelhantes às do tecelão, e a abelha supera mais de um arquiteto ao construir sua colmeia. Mas o que distingue o pior arquiteto da melhor abelha é que ele figura na mente sua construção antes de transformá-la em realidade. No fim do processo do trabalho aparece um resultado que já existia antes idealmente na imaginação do trabalhador. Ele não transforma apenas o material sobre o qual opera; ele imprime ao material o projeto que tinha conscientemente em mira, o qual constitui a lei determinante do seu modo de operar e ao qual tem de subordinar sua vontade. E essa subordinação não é um ato fortuito. Além do esforço dos órgãos que trabalham, é mister a vontade adequada que se manifesta através da atenção durante todo o curso do trabalho. $\mathrm{E}$ isto é tanto mais necessário quanto menos se sinta o trabalhador atraído pelo conteúdo e pelo método de execução de sua tarefa, que lhe oferece, por isso, menos possibilidade de fruir da aplicação das suas próprias forças físicas e espirituais (MARX, 2008, p. 212). 
Diante dessa categorização marxiana ${ }^{4}$ sobre trabalho, partimos do pressuposto de que o desenvolvimento da arte sempre esteve atrelado ao trabalho humano e viceversa. O homem pré-histórico criava utensílios que Ihes serviam ao dia a dia, os quais revelavam quem ele era e como agia no mundo, da mesma forma que também criava objetos que poderiam não ter serventia para nada, mas apenas para expressar seus sentimentos bem como afirma Proença $(2012$, p. 6): "o ser humano, seja de que época for, cria objetos não apenas para se servir deles, mas também para expressar seus sentimentos diante da vida".

E como prova de que arte e trabalho se entrelaçam desde sempre, a Associação das Artesãs Ribeirinhas de Santarém realiza com destreza essa combinação que envolve um modo de fazer e agir na natureza aliado a parâmetros artísticos que resultam em maiores expectativas de vida e melhorias para os envolvidos. Vázquez (2011) assinala que a relação entre o homem e a natureza é permeada pelas forças do trabalho e este transforma a natureza de tal modo que desta ação nascem objetos que satisfazem as necessidades do homem, entretanto, dada a natureza social dos seres humanos, são necessárias condições objetivas para que esse processo ocorra, como os elementos da natureza, os interesses dos homens, diante de uma necessidade, e a projeção humana em prol da satisfação dessa necessidade. E no contexto da Associação que serviu de espaço de ensino e aprendizagem para os discentes da EJA com os quais essas condições foram observadas, pois as mulheres da Associação em prol de seus interesses e necessidades se organizaram e, por meio do trabalho, iniciaram uma práxis produtiva:

(...) houve uma mobilização de mulheres artesãs de cinco comunidades de Aritapera, em torno de um objetivo comum: melhorar a qualidade de vida de suas famílias, a partir da comercialização de seu artesanato e pelo reconhecimento de seu trabalho desenvolvido (MADURO, 2012, p. 33).

Além disso, Vázquez (2011) ainda sustenta a ideia de que as criações resultantes da intervenção humana na natureza, como as realizadas pelas mulheres da Associação aqui em observação, são repletas de características que revelam o próprio homem e sua forma de ser. Em sua prática para se chegar a um fim determinado, o homem desloca para seu projeto muito de sua subjetividade e esta é uma das principais características do trabalho, a humanização, já que tudo o que está relacionado a este fim é repleto de

\footnotetext{
${ }^{4}$ Utilizamos o presente termo para denotar reflexões pautadas nas leituras de Marx. Não se trata, pois, de expressão para referenciar o que marxistas escrevem a partir de Marx.
}

Revista Digital do LAV - Santa Maria - vol. 8, n. 3, p. 48 - 72. - set./dez. 2015 ISSN $1983-7348$ http://dx.doi.org/10.5902/1983734820532 
interferências do homem, tanto os instrumentos utilizados para se trabalhar quanto os objetos resultantes desse trabalho.

Vázquez (2011) também adiciona a arte na relação humana com o trabalho à medida que, ao imprimir sua personalidade em seus objetos, o homem não o faz apenas para satisfazer suas necessidades diárias, mas o faz também para se expressar e comunicar. Assim, ao observarmos, com os alunos com os quais trabalhamos a disciplina Artes na Escola de Santarém que tomamos como locus de nossas ações pedagógicas, percebemos que as "pintas" (incisões) impressas nas obras das mulheres do Aritapera eram mais que adornos ou mera decoração; há nesses traços uma história sobre quem são essas mulheres e suas origens. Uma pessoa que adquire um produto artístico produzido pelas artesãs saberá, por meio das características desse objeto, muito da realidade dessas mulheres e a que cultura elas pertencem, pois quando se tem essa percepção impressa nos objetos, temos então a arte que revela o mundo ao seu redor.

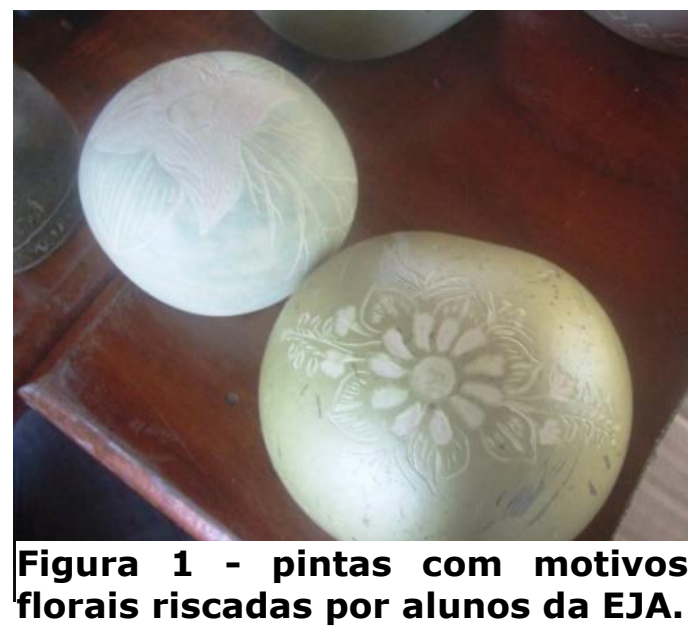

Para os propósitos deste trabalho, entendemos que a arte é mais que uma atividade meramente espiritual; ela é uma unidade teórico-prática e está intimamente ligada ao homem pelas relações de trabalho. A arte é resultado do trabalho do homem que, pensando no bem comum e a partir de uma matéria prima, cria outra forma para se expressar diante do mundo e para se estabelecer enquanto ser que cria outras realidades, sempre melhores que as anteriores, como expresso nas palavras de Lélia Maduro, presidente da ASARISAN: "tendo uma associação nós teríamos mais força, nós poderíamos ter autonomia especialmente em cima do nosso trabalho na questão comercial". Portanto, conclui-se a praticidade da arte promovida pelo trabalho coletivo que sempre tem em vista a transformação de uma situação, sempre para o bem comum.

Revista Digital do LAV - Santa Maria - vol. 8, n. 3, p. 48 - 72. - set./dez. 2015 ISSN 1983 - 7348 http://dx.doi.org/10.5902/1983734820532 


\section{A ARTE ENQUANTO PROCESSO DE ENSINO}

Fruto de nossas ações docentes enquanto educador ligado às artes e presente no ensino público do Estado do Pará, destacamos nesta segunda seção um conjunto de reflexões que resultam de nossas experiências como educadores, vivenciando os desafios estruturais, pedagógicos, afetivos, dentre outros, para o exercício do magistério quanto ao ensino e aprendizagem de objetos de conhecimento e de ensino. Expomos ainda que o ensino da arte nas escolas públicas sempre passou e passa por grandes discussões quanto a sua forma de ser em sala de aula.

Uma organização curricular que garanta o teatro, a dança, a música e as artes visuais em suas especificidades e com professores específicos - formação na área -, ainda é muito incipiente e o que acontece no âmbito escolar de fato é uma forma ultrapassada para se praticar as artes, tanto na teoria quanto na prática. Como bem assinalam os PCN (1998) para o ensino das artes, existe uma considerável distância entre a teoria e a prática em sala de aula porque há uma defasagem de conhecimentos por parte dos professores, no sentido de uma falta de formação específica para diferentes espaços formativos na área de artes.

Na perspectiva dos jovens e adultos, as artes têm que possibilitar aos sujeitos uma vivência que permita entender cada etapa da produção artística, além de fazer com que com os alunos possam refletir sobre sua própria existência dentro do universo.

A educação visual deve considerar a complexidade de uma proposta educacional que leve em conta as possibilidades e os modos pelos quais os alunos transformam seus conhecimentos de arte, ou seja, o modo como aprendem, criam, desenvolvem-se e modificam suas concepções de arte. (PCN, 1998, p. 63)

Ou seja, os parâmetros para o ensino da arte alertam para uma educação que desperte nos alunos a sensibilidade para entender os ambientes e os objetos a que são expostos diariamente, já que transmitem sensações, emoções, ideias etc. Pensar no ensino das artes visuais partindo desse pressuposto permite entender mais ainda o mundo ao qual se está inserido e de uma perspectiva mais crítica.

E foi a partir deste intuito que os alunos da EJA da escola Nazaré Demétrio Mussi foram envolvidos na realização trabalhos artísticos realizados no final do primeiro semestre de 2013, especificamente nos dias 22 e 23 de junho, na Associação das Ribeirinhas de Santarém, Centro do Aritapera, uma das comunidades que fazem parte da Região do Aritapera e onde fica localizada a sede da Associação. Após o início das aulas, foi anunciado

Revista Digital do LAV - Santa Maria - vol. 8, n. 3, p. 48 - 72. - set./dez. 2015 ISSN 1983 - 7348 http://dx.doi.org/10.5902/1983734820532 
aos alunos que a disciplina de Artes culminaria em uma atividade prática, fora de sala de aula, uma viagem de natureza artística e cultural para se conhecer o trabalho da ASARISAN na produção das cuias artesanais, importante ícone da cultura e culinária paraense.

As oportunidades de aprendizagem de arte, dentro e fora da escola, mobilizam a expressão e a comunicação pessoal e ampliam a formação do estudante como cidadão, principalmente por intensificar as relações dos indivíduos tanto com seu mundo interior como com o exterior (PCN, 1998, p. 19)

As aulas da disciplina Artes com os alunos da EJA aconteciam apenas uma vez por semana, às quartas-feiras, em dois tempos de 45 minutos mais que mínimos e corridos. Além dos conteúdos já estabelecidos pelo programa ${ }^{5}$, era preciso encontrar tempo para articular as ideias e saber quais as expectativas dos alunos. Comumente se "roubavam" umas aulas de língua portuguesa (maior hora/aula) para a expansão das atividades ${ }^{6}$.

Dadas as peculiaridades dos alunos da Educação de Jovens e Adultos, estar diariamente em sala de aula é uma batalha constante entre novas perspectivas sobre o mundo ou a continuação de uma vida destinada ao insucesso, com destaque para esta última. Ao término do semestre, quase metade deles havia evadido. Trata-se de uma juventude impedida de viver a juventude em sua plenitude, conforme exposto por Frigotto (2004). Segundo esse autor, tomando como referência suas reflexões sobre juventude, trabalho e educação no Brasil, a juventude deve ser compreendida como uma fração da classe trabalhadora que vem sendo impedida de vivenciar sua fase de formação com qualidade, em decorrência de desde cedo estar submetida por razões estruturais ao emprego ou subemprego, a fim de contribuir com a renda familiar. Para o autor, a juventude trabalhadora é resultante de "[...] uma unidade do diverso econômico, cultural, étnico, de gênero, de religião etc." (FRIGOTTO, 2004, p. 181).

Ainda segundo Frigotto (2004), a juventude brasileira constitui-se de jovens que pertencem "[...] à classe ou fração de classe de filhos de trabalhadores assalariados ou que produzem a vida de forma precária por conta própria, no campo e na cidade $[\ldots]$ " em diferentes regiões e com "particularidades socioculturais e étnicas" diversas (FRIGOTTO, 2004, p. 181).

\footnotetext{
5 Organizava-se em quatro módulos, um para cada bimestre, e que correspondiam apenas a assuntos introdutórios, meramente teóricos sobre o teatro, a dança e as artes visuais. A música não era contemplada.

${ }^{6}$ Nós também ministrávamos as aulas de língua portuguesa (maior hora/aula) e, comumente, discussões sobre o projeto de artes eram realizadas dentro dos encontros de português.
}

Revista Digital do LAV - Santa Maria - vol. 8, n. 3, p. 48 - 72. - set./dez. 2015 ISSN 1983 - 7348 http://dx.doi.org/10.5902/1983734820532 
Considerando a situação acima exposta e diante de uma turma apática para artes, diagnóstico obtido por meio de conversa formal no primeiro dia de aula a despeito do que os alunos esperavam acontecer e tendo como resposta a passividade e a falta de interesse, precisou-se pensar em algo que deixasse a classe interessada em fazer e, ao mesmo tempo, que lançasse luz diante dos passos de jovens notadamente desinteressados pela arte.

A ideia de viajar para uma comunidade às margens do Rio Amazonas, conhecer o contexto de produção, conviver com as pessoas envolvidas no fazer artístico, saber de suas histórias e poder fazer parte do processo de criação dos objetos artísticos agradou aos alunos e garantiu-Ihes novos comportamentos diante da disciplina. $O$ fato é que a escola tem a missão de organizar ações que garantam aos alunos o contato com a produção visual, mais que isso, tem que proporcionar formas de aprendizagem que se consolide na prática visual de diferentes culturas.

Aos poucos, no entanto, a ideia central do projeto de apenas perceber a arte nos trabalhos das artesãs foi sendo transformada para também se perceber todo o processo anterior de trabalho até se chegar à arte. Era preciso entender o projeto mais que uma viagem ou uma mera apreciação do resultado final; a intenção era fazer os alunos entenderem que o trabalho também poderia levar à arte como resultado final e que eles também poderiam trabalhar para a arte. Nesse sentido, Rodrigues (2012, p. 54) afirma

[...] que pelo trabalho o homem se constitui, demarca sua identidade, sua personalidade, seu modo de vida, sua subjetividade e objetividade. Sua subjetividade porque, por meio do trabalho, o homem vai estabelecendo valores, concepções de mundo, saberes; objetividade porque, por meio do trabalho, o homem também vai moldando o mundo, a realidade material, tanto a objetos físicos quanto ao ser social, sendo capaz de projetar e materializar, concomitantemente, essa realidade.

A turma toda sentia o impacto de estudar e trabalhar ao mesmo tempo e entender o trabalho como elemento de transformação era fundamental; perceber sua importância pelo viés da arte e vice-versa era necessário para a criação de novas expectativas e a opção de um caminho a mais para cada aluno.

No decorrer do semestre surgiu a ideia de se fazer uma espécie de documentário sobre a viagem no qual a oficina7 ${ }^{7}$ seria filmada e as artesãs entrevistadas a respeito de seus trabalhos. Diante da aceitação da ideia, foi esclarecido que os alunos é quem

\footnotetext{
7 Organizada pelas artesãs em dois dias para ensinar os alunos, passo a passo, sobre como se produzir uma cuia, desde a colheita da cabaça até às incisões, incluindo aí também explicações teóricas a respeito desse trabalho.
}

Revista Digital do LAV - Santa Maria - vol. 8, n. 3, p. 48 - 72. - set./dez. 2015 ISSN 1983 - 7348 http://dx.doi.org/10.5902/1983734820532 
realizariam a entrevista e para isso todos elaboraram perguntas que envolveram diversas categorias: arte, trabalho, história de vida, tempo de tralho etc. Abaixo, um conjunto de indagações ${ }^{8}$ realizadas pelos discentes junto às artesãs:

1-Como surgiu o trabalho com as cuias aqui no Aritapera?

2-Com quem a senhora aprendeu a fazer cuia?

3-Como surgiu a ideia de se montar uma Associação Das Artesãs Ribeirinhas de Santarém? 4-A senhora considera as cuias um trabalho artístico?

5-Ao ver as cuias produzidas que sentimento toma conta da senhora?

6-O que motiva a sua participação nessa atividade artística?

7-Vocês se reúnem com frequência?

8-E vocês se reúnem apenas para a produção de cuias ou discutem também outros temas?

9-Como é feita a divulgação das cuias?

10-Como é a comercialização das cuias artesanais?

11-Existe algum tipo de intercâmbio de vendas das cuias com outros países?

12-Como é dividido o lucro da Associação?

Diante de mais conhecimentos obtidos a respeito da Associação e com mais afinidade sobre o projeto, acordou-se com os alunos que todos aqueles que participassem do projeto teriam a nota máxima na segunda avaliação (somativa) ${ }^{9}$. Entretanto, para além dos números, a avaliação considerou dois critérios sugeridos pelos PCN (1998, p. 69): estabelecer relações com o trabalho de arte produzido por si, por seu grupo e por outros sem discriminação estética, artística, étnica e de gênero. Com este critério os alunos foram orientados e introduzidos ao respeito para com os valores estéticos de outros grupos; identificar os elementos da linguagem visual e suas relações em trabalhos artísticos e na natureza. Neste os alunos foram estimulados a perceber características das artes visuais dentro dos objetos de criação (as cuias).

Esclarecidos todos os pontos pendentes com os alunos e com a escola, pontos estes que envolveram cozinheiras, pessoal de apoio e presença da direção, no dia 22 de junho de 2013, às 8 horas da manhã, os alunos da EJA $4^{a}$ etapa e demais envolvidos partiram da escola Nazaré Demétrio Mussi rumo ao porto de Santarém para uma viagem de barco, de aproximadamente 3 horas ao Centro do Aritapera, local destinado à oficina.

\footnotetext{
${ }^{8}$ As indagações criadas pelos discentes, a partir de orientação docente, seguiram as orientações da construção da entrevista semiestruturada ou não-diretiva nos moldes propostos por Michelat (1985), sendo analisadas pela Análise de conteúdo (FRANCO, 2007).

${ }^{9}$ De natureza tradicional, somativa e para atender ao modelo avaliativo da escola.
}

Revista Digital do LAV - Santa Maria - vol. 8, n. 3, p. 48 - 72. - set./dez. $2015 \quad$ ISSN 1983 - 7348 http://dx.doi.org/10.5902/1983734820532 


\section{ARTE E TRABALHO NO CONTEXTO AMAZÔNICO}

Na fotografia abaixo, observa-se o contexto amazônico de casas envolvidas pelos rios, com o seu modo de existência que toma o fluxo das marés e a natureza como elementos importantes para a constituição do sujeito que constitui esse universo. É a várzea Santarena. Banhada pelo Rio Amazonas e que durante 6 meses cresce seu volume de água deixando toda a região submersa, situação normalizada nos demais meses do ano. Foi nesse contexto que os discentes da EJA sob nossa ação pedagógica vivenciaram a experiência didática de articular trabalho e artes no campo do ensino e de aprendizagem, a partir da Associação de Artesãs de Santarém-Pará.

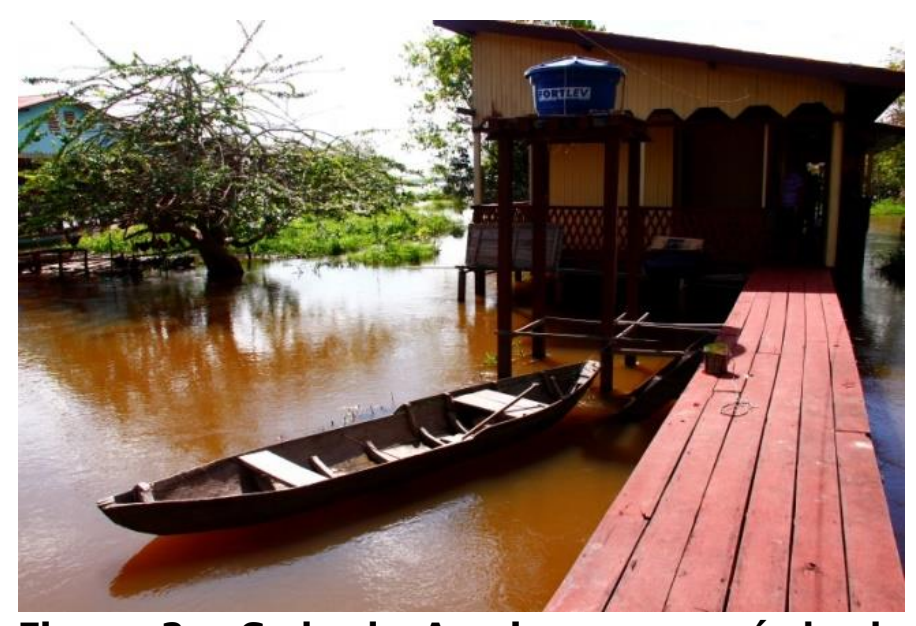

Figura 2 - Sede da Asarisan, no período de cheia do Rio Amazonas.

Diante de um processo de desvalorização ${ }^{1011}$ das cuias pelo comércio local, em 2003 a ASARISAM (Figura 2) foi criada para a produção de cuias artesanais e outras peças de melhor qualidade e ingresso em outros mercados, além de resgatar sua forma original de ornar as cuias inspiradas nas tradições indígenas de seus antepassados. Tem-se aí a manutenção de uma cultura que é arte ao mesmo tempo em que se tem uma fonte

\footnotetext{
10 Júnior (2012, p. 76) explica que: "Antes da criação da associação, as artesãs viviam um processo de desvalorização de sua produção do comércio local, consequência de, entre outros fatores, crescente demanda por cuias lisas por parte de artesãos urbanos de Santarém e Monte Alegre, que as utilizavam nuas como matéria prima para a confecção de artigos variados."

${ }_{11}$ Diante do processo de desvalorização, ainda segundo Júnior (2012), as artesãs tiveram que se adaptar a esta realidade, atuando apenas como produtoras primárias (de cuias lisas) e este fato contribuiu para um certo esquecimento dos ornamentos característicos deste trabalho.
}

Revista Digital do LAV - Santa Maria - vol. 8, n. 3, p. 48 - 72. - set./dez. 2015 ISSN 1983 - 7348

http://dx.doi.org/10.5902/1983734820532 
financeira de sobrevivência. As cuias artesanais aí produzidas são expostas e comercializadas, além de Santarém e Belém, para os estados de São Paulo, Rio de janeiro e Santa Catarina. Recentemente o modo de fazer cuias no Baixo Amazonas - região oeste do estado do Pará que engloba 12 municípios incluindo Santarém - prática indígena já registrada desde o final do século XVII entre as etnias Yurimagua e Aizuare, passou a fazer parte do Patrimônio Cultural Brasileiro, do Instituto do Patrimônio Histórico e Artístico Nacional - IPHAN.

No local destinado aos trabalhos, reuniram-se corpo escolar e artesãs: Lélia Maduro (presidente), Cecília Corrêa, Avanilda Pereira, Angeli Azevedo e Raimunda Azevedo. Logo se iniciaram os trabalhos práticos que envolveu, antes de mais nada, uma explicação prévia sobre instrumentos e a matéria prima do trabalho, a cuia, fruto da cuieira (crescentia cujete), já que "a educação em artes visuais requer entendimento sobre os conteúdos, materiais e técnicas com os quais se esteja trabalhando" (PCN, 1998, p. 63).

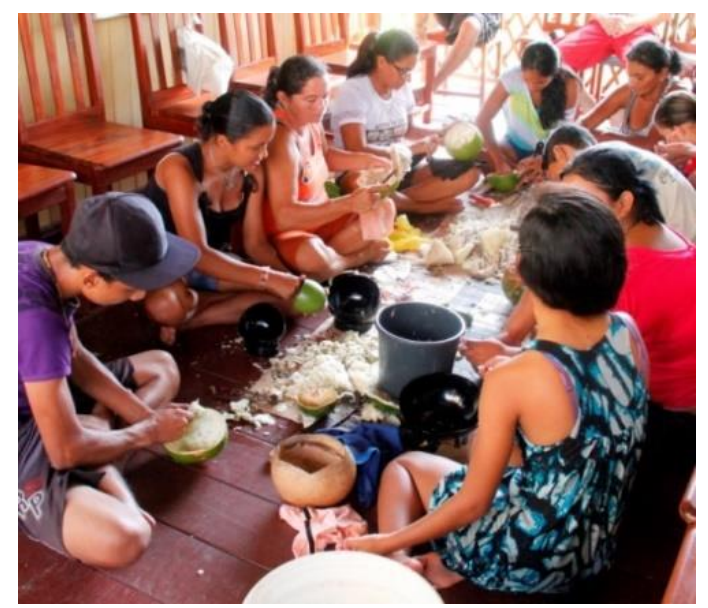

Figura 3 - Raspagem das cabaças, sob orientação das artesãs.

O processo inicial de transformação das cabaças é dividi-las ao meio, mas pode ser cortada a partir de outros ângulos a depender do que vá se transformar. A Figura 3 demonstra os alunos "retirando o bucho" ou o miolo, trabalho que consistiu na limpeza de toda a matéria orgânica presente na parte interna. Para isso, foram utilizados instrumentos adaptados pelas próprias artesãs, lâminas feitas da parte oval de colheres.

Adiante, escamas de pirarucu foram usadas como instrumentos de continuidade ao processo de lixa das cuias (Figura 4). Passada de forma exaustiva por toda a sua superfície interna e externa, a escama garante a eliminação de qualquer distorção, possibilitando uma superfície. Cada etapa do trabalho que antecede a arte é de extrema

Revista Digital do LAV - Santa Maria - vol. 8, n. 3, p. 48 - 72. - set./dez. 2015 ISSN 1983 - 7348 http://dx.doi.org/10.5902/1983734820532 
importância e constitui um princípio para o ensino das artes visuais e para as perspectivas dos alunos:

O desenvolvimento do aluno nas linguagens visuais requer, então, aprendizagem de técnicas, procedimentos, informações sobre história da arte, artistas e sobre as relações culturais e sociais envolvidas na experiência de fazer e apreciar arte. Sobre tais aprendizagens o jovem construirá suas próprias representações ou ideias, que transformará ao longo do desenvolvimento, à medida que avança no processo educacional. (PCN, 1998, p. 64)

O passo seguinte consistiu em uma última lixa nas cuias em que os alunos utilizaram folhas de imbaúba (de textura aveludada) em um longo processo que garantiu ao produto um toque macio. A partir deste ponto, foi explicado aos alunos que as cuias poderiam ser tingidas ou permanecer daquele jeito mesmo, apenas ganhando os riscos ornamentais.

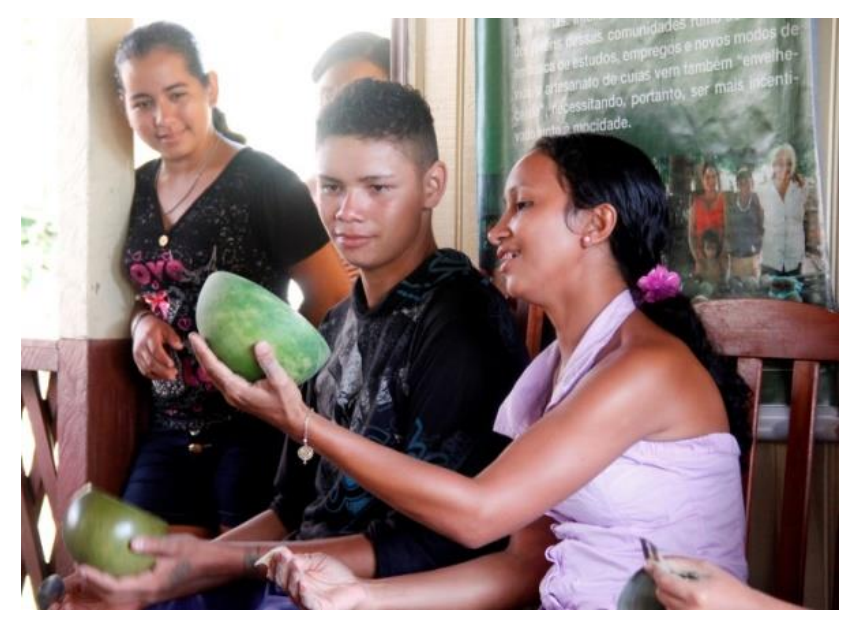

Figura 4 - Alunos da EJA lixando as cuias.

A última parte da oficina consistiu em dois módulos: o primeiro destinado às cuias naturais, sendo estas finalizadas apenas com os riscos (Figura 5), processo este explicado com cautela pelas artesãs, já que envolveu o uso de um instrumento pontiagudo (também desenvolvido pelas próprias mulheres) para se traçar motivos indígenas, geométricos e outros como flores; o segundo módulo consistiu no tingimento das cuias com o cumatê, tinta natural extraída do axuazeiro ${ }^{12}$ e neste processo foram usadas penas de galinha para garantir pinceladas suaves que não deixam marcas já que a qualidade é uma das marcas da Associação.

\footnotetext{
12 Árvore comum na Amazônia e da casca da qual, por meio de um processo manual, se extrai o cumatê, tinta natural utilizada para o tingimento das cuias.
}

Revista Digital do LAV - Santa Maria - vol. 8, n. 3, p. 48 - 72. - set./dez. 2015 ISSN 1983 - 7348 http://dx.doi.org/10.5902/1983734820532 
O processo de tingimento das cuias dura por volta de uma semana, pois até se chegar ao preto cintilante, cor desejada, são passadas muitas demãos de tinta. Tingimento pronto, as cuias são expostas a uma mistura de cinzas e amônia (extraída da urina humana), reação que garante a fixação da cor. Finalmente as cuias estão prontas para os riscos, uma atividade manual que requer firmeza nas mãos e ao mesmo tempo sensibilidade e criatividade para um traçado perfeito.

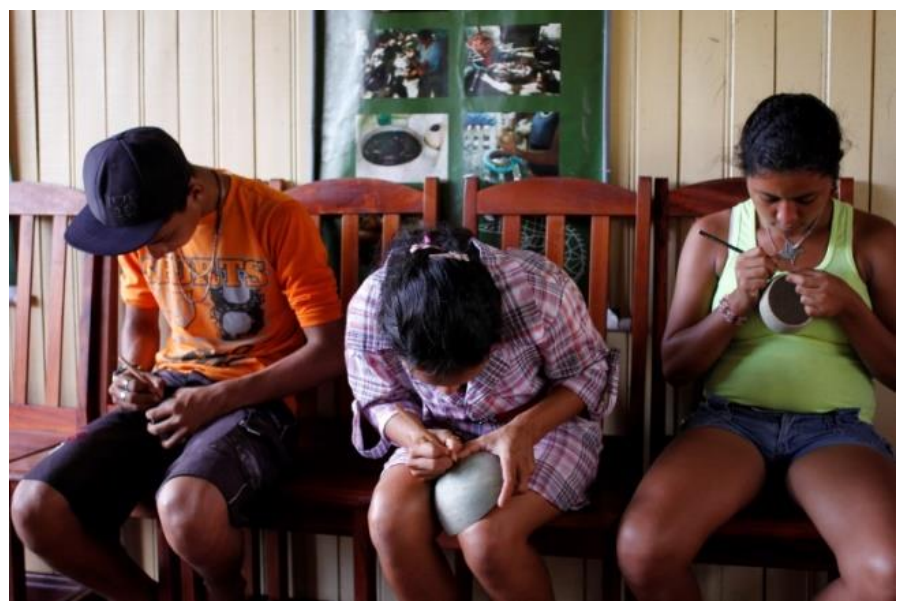

Figura 5 - Incisão das cuias naturais.

Obviamente que os alunos não acompanharam todo o processo tingimento e fixação da cor dado o seu longo tempo, em média uma semana para os padrões da Associação, mas o fizeram de forma parcial. As artesãs disponibilizaram algumas peças tingidas para os alunos riscarem como demonstração de qual a cor desejada e de que maneira podem ser riscadas. A Figura 6 demonstra o resultado dos trabalhos dos alunos.

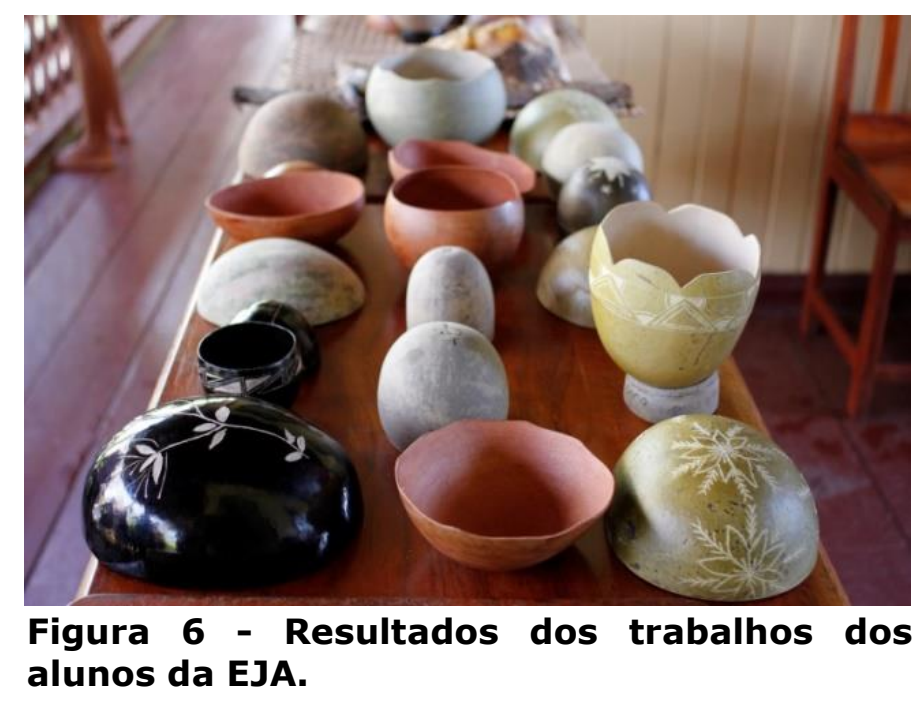

Revista Digital do LAV - Santa Maria - vol. 8, n. 3, p. 48 - 72. - set./dez. 2015 ISSN 1983 - 7348 http://dx.doi.org/10.5902/1983734820532 
Por toda a manhã do dia 23 de junho, os alunos se concentraram em torno da entrevista com Lélia Maduro, presidente da ASARISAN, e com outras artesãs. Diante das câmeras e seriedade da ocasião, nem todos quiseram participar alegando vergonha. Os alunos conheceram sobre a história pessoal de cada artesã e como elas foram introduzidas na cultura das cuias, entenderam por quais motivos surgiu a ASARISAN, além das relações de capital aí existentes.

Em termos históricos, por exemplo, os discentes, entrevistando as artesãs, dialogando, vivendo a arte no trabalho e pelo trabalho, compreenderam o processo de trabalho com cuias por parte das artesãs. Segundo a artesã Lélia Maduro, a partir da indagação de um dos discentes da EJA,

"[...] desde nossos antepassados havia esse trabalho de cuia, mas de início só [era] banda de cuia. Pegava uma cuia, partia ao maio e o pessoal comprava mais pro tacacá, pro tarubá, pro mugunzá, pro açaí (...). E esse processo veio se passando de nossos antepassados e está até hoje só que já num outro processo, num outro modelo diferente".

No tocante ao trabalho com as cuias, os discentes entenderam que o processo de ensino e de aprendizagem resulta de uma relação familiar, que vai possibilitando a ampliação de conhecimentos, novas realidades artísticas, conforme relata a artesã Cecília Corrêa, que informa que aprendera a arte do trabalho com cuias com a mãe, a partir do que passara a ampliar sua formação: "Com minha mãe. Ela trabalhava muito com cuia, mas ela não fazia essas peças diferentes, ela fazia cestas e gostava muito de fazer isso. Aí eu fui aprendendo com ela. Mas eu não gosto de fazer cesta porque sempre quebra". E no dizer da artesã Avanilda Pereira: "Eu aprendi com minha avó e com minha tia. Eu era menina e ficava lá junto delas e isso me motivou". E no dizer da artesã Angeli Azevedo: "Eu aprendi com minha mãe, desde a idade de 12 anos eu trabalho nas cuias. Após a Associação eu comecei a fazer outros modelos de cuia".

Não menos importante esteve a compreensão que os discentes da EJA puderam ter sobre como o trabalhador percebe o seu trabalho enquanto objeto artístico e produtor também de sua sobrevivência, tratando-se, nesse sentido, de se compreender que o homem, pelo trabalho, imprime à natureza as suas objetivações e subjetivações. Indagadas sobre o trabalho com as cuias ser um trabalho artístico, as artesãs relataram, como Cecília Corrêa: "Eu considero, porque das cuias a gente faz qualquer arte. Nem todas as cuias servem pra gente fazer certas artes, mas tem muitas que faz boneco, vasos...tudo é arte". A artesã Avanilda Pereira destaca: "Considero sim porque nem todas as pessoas 
sabem fazer. Quando a gente cria uma coisa, é uma arte e nem todos tem essa habilidade". A artesã Angeli Azevedo enfatiza: "Considero sim. Eu admiro a beleza dela [a cuia] porque está acabada, tá bem feitinha, aperfeiçoada".

Outra questão importante foi o acesso dos discentes à história do processo de organização das mulheres que militam na produção das cuias como arte e objetos de mercado. Trata-se de o ensino e aprendizagem possibilitar o reconhecimento da materialidade histórica que permeia a construção da arte. A esse respeito, a artesã Lélia Maduro destacou aos discentes que

A ideia de se criar as Artesãs Ribeirinhas de Santarém se deu pela motivação da antropóloga Luciana Carvalho que veio pesquisar onde se trabalhavam nas cuias e tentar fazer um resgate da cultura. $O$ SEBRAE de Santarém e Belém ficou também motivando pra que nós tivéssemos uma associação e tendo uma nós teríamos mais força e autonomia especialmente em cima do nosso trabalho na questão comercial.

Sobre o processo de organização do trabalho, no sentido de compreender como as artesãs realizam a produção das obras de arte que ao longo dos anos se coloca no mercado como forma de garantir a existência da comunidade, a partir do trabalho das mulheres artesãs, Lélia Maduro destaca: "Nós nos reunimos em núcleo de produção. É semanal, de segunda a sexta. Quando a gente tem uma demanda maior, vai até o sábado. Mas quando não tem demanda grande, a gente trabalha num horário [e] no outro não". Mas Lélia Maduro também expôs aos discentes, a partir das entrevistas, que elas não se reúnem somente para a produção de cuias, mas também para tratar de outras temáticas, numa demonstração de que pelo trabalho com a arte os homens produzem a existência, como também atos políticos, sociais, econômicos:

A gente reúne pra produção das cuias e também reúne pra discutir outros temas. Sempre nos vêm propostas de algum projeto e a gente reúne pra poder analisar e dar uma resposta. Quando é encomenda às vezes é padronizada, então a gente precisa ver direitinho, reunir e discutir o valor pra poder dar a resposta pro cliente. E pra dar uma resposta a gente primeiro ver se tem a matéria prima pra atender o pedido.

Também os discentes puderam refletir, a partir dessa experiência de ensino e de aprendizagem, por meio do contato com a Associação das Artesãs Ribeirinhas de Santarém, como ocorre o processo de divulgação do trabalho que a Associação realiza, de modo a compreender diferentes processos que podem acompanhar a produção artística quando a mesma ultrapassa a relação homem e obra de arte para se constituir em ação

Revista Digital do LAV - Santa Maria - vol. 8, n. 3, p. 48 - 72. - set./dez. 2015 ISSN 1983 - 7348 http://dx.doi.org/10.5902/1983734820532 
de mercado, podendo aí demonstrar-se um processo de alienação do produto e da atividade, de que tratamos na primeira seção deste trabalho, a partir de Marx (2008). A esse respeito, a artesã Lélia Maduro expõe que no início da fundação da Associação a divulgação

[...] se deu através do SEBRAE Santarém e Belém; no São José Liberto (Belém) que tem um espaço de exposição; no Rio de Janeiro, na sala do artista popular que se localiza no museu Édson Carneiro; no Centro Nacional de Folclore e Cultura Popular (Rio de Janeiro); se dá também nas exposições (Museu de Artes e Ofícios em Belo Horizonte); na Artesol em São Paulo; nós estivemos no projeto Saúde e Alegria; no terminal turístico [de Santarém], mas não deu muito certo e nós paramos; nós temos o site (airacuias.blogspot.com) também que há já uma ampla divulgação.

Na mesma direção, a artesã Lélia Maduro destacou o processo de comercialização da produção de cuias, o que demonstra a alienação da produção, porque o objeto artístico assume uma fetichização ${ }^{13}$, conforme Marx (2008), sendo destituído das funções outrora existentes para o produtor, em termos de necessidades imediatas, para se constituir um objeto do mercado: "A comercialização se dá pelo site, por e-mail, os clientes entram em contato com a Rubia Gorete (assessora da ASARISAN) ou ligam diretamente pra gente e daí se faz a negociação. Também acontece nas exposições. Em São Paulo a Artesol promove o intercâmbio com os clientes". E ainda destaca sobre o comércio realizado: "Nós já atendemos pedidos pra França, Suíça, Argentina e outros países".

Em termos dos resultados da comercialização, Lélia Maduro expôs aos discentes como ocorre a divisão dos lucros obtidos com o comércio das cuias.

Quando é um pedido padrão, cada núcleo recebe uma quantidade certa de peças. Esse pedido tem um preço só. A gente tira o fundo pra Associação e manda o valor correspondente a quantidade de peças que cada núcleo produziu. Agora quando é exposição, cada núcleo faz o seu produto da maneira que acha...peças diversificadas: pequenas, grandes. E conforme a peça, agrega-se valor. Neste caso não é o mesmo valor pra cada núcleo. Cada núcleo pega a renda daquela quantidade que mandou [produziu]. Nós tínhamos, no caso, um pedido padronizado de uns copinhos. Teve núcleo que não tinha esse tamanho. Então nós distribuímos para os núcleos que tinham porque assim ficou combinado: quando não tivéssemos matéria prima pra atender aquele padrão, a gente daria

\footnotetext{
${ }^{13}$ A fetichização acontece, segundo Marx (2008), quando um produto perde seu valor de trabalho humano e passa a constituir outra perspectiva que se relaciona ao objeto de desejo, ou seja, um produto passa a ser visto por uma ótica que o tira seu valor material e adiciona a este produto o caráter de representatividade, status ou mesmo simbolismo.
}

Revista Digital do LAV - Santa Maria - vol. 8, n. 3, p. 48 - 72. - set./dez. 2015 ISSN 1983 - 7348 
pra outro núcleo. E depois a gente faz uma troca, quando vem um outro pedido aquele núcleo que não fez já vai fazer peças também.

Sobre a relação com o objeto artístico, agora assumindo a posição de objeto de comercialização que assume valor de arte para o comprador e também para o produtor, num processo dialético de negação/afirmação desse elemento artístico, a artesã Avanilda Pereira destaca: "Eu fico alegre porque não demora e eu vou vender elas pra ganhar dinheiro", enquanto que a artesã Angeli Azevedo salienta: "Eu já vou preparada pra vender e pegar o dinheiro".

Sobre processos de envolvimento das trabalhadoras na atividade de trabalho também permeada pelo elemento artístico, a artesã Avanilda Pereira salienta: "Ganha dinheiro. Também eu aprendo muitas coisas. Há uma união com todas as mulheres, nós nos tornamos mais amigas depois da Associação. [Tem] alegria e mais conhecimento, a coisa mais importante". E Angeli Azevedo ressalta: "Eu gosto do trabalho que eu faço e isso vem me motivar pra eu continuar participando".

Isto posto, destacamos que toda essa experiência possibilitada aos alunos por meio da convivência com as mulheres artesãs do Aritapera é o que Vásquez (2011) classifica como oportunização a uma vivência teórico-prática enquanto unidade. Os alunos vivenciam a arte onde o objeto da criação acontece. O potencial desse tipo de atividade possibilitou aos sujeitos terem acesso àqueles que vivenciam a produção artística, pois ao se levar os aprendizes aos mestres de ofícios, para quem a cultura, mesmo mercantilizada como constatada nas entrevistas, ainda se reserva o direito de demonstrar a identidade de uma relação do homem urbano com o ribeirinho e deste com os rios e com a natureza.

Permitiu-se compreender também as relações de companheirismo presentes na produção artística, relatada nas palavras de Avanilda Pereira ao citar a união entre as artesãs após a criação da Associação, coadunando-se com as palavras de Rodrigues (2012, p. 55) ao afirmar que

é pelo trabalho que o homem se organiza e se articula com outros homens, a fim de controlar a natureza, objetivando, na perspectiva dos trabalhadores, uma realidade pautada pela primazia do reino da liberdade, direcionada para a emancipação humana.

Práticas como esta potencializam uma formação para o além do aqui e agora de uma sala de aula, garantindo àqueles da educação de jovens e adultos novos olhares sobre o universo da arte. Observamos ainda que impregnada ficou nos alunos a percepção de que o homem é um todo "essencialmente, por seu ato criador, em qualquer das formas de conhecimento humano (...) respondendo aos desafios que dele emanam, em um constante

Revista Digital do LAV - Santa Maria - vol. 8, n. 3, p. 48 - 72. - set./dez. 2015 ISSN 1983 - 7348 http://dx.doi.org/10.5902/1983734820532 
processo de transformação de si e da realidade circundante" (PCN, 1998, p. 30) porque as artes possibilitam essa compreensão.

Outrossim, entendemos que neste contexto o objeto da criação perdeu sua perspectiva absolutamente artística e passou para o âmbito do mercado, afinal, é a fonte de renda das artesãs. Esse fato pode afetar o artista à medida que sua obra deixa de ter um valor apenas artístico, no entanto, o que se conta aqui é uma formação sobre as artes para além do fazer ou do simplesmente apreciar a arte; é a formação de um sujeito jovem e adulto crítico que entende as relações de mercado que permeiam a produção artística.

E mesmo mercantilizada, os aprendizes perceberam que a produção das artes na referida comunidade não se mercantilizou absolutamente já que ainda preserva o caráter do artesão, aquele que domina a totalidade da produção artística, ou seja, as senhoras da Associação são capazes de ir do início ao fim na produção de uma cuia, passando por todas as etapas do trabalho.

\section{CONSIDERAÇÕES FINAIS}

A educação de jovens e adultos em nosso país foi se instituindo gradativamente ao longo da história. Em 1823 já se encontram esboços educacionais visando uma educação de melhor qualidade e para todos por meio do Método Lancaster. As décadas seguintes juntamente com todo o século XX foram marcadas por avanços importantes que, quando somados, consolidam formalmente a EJA dentro do cenário atual da educação. Paiva (2006, p. 24-25) afirma que

a educação de jovens e adultos ganhou oficialmente, ao longo de pouco mais de meio século, novos sentidos e concepções, produzidos no interior dos países, nas tensões sociais, em tentativas de reafirmação de direitos de maiorias vistas, na sociedade desigual, como minorias.

Todas as conquistas alcançadas ao longo de mais de um século não significam, no entanto, que a EJA não enfrente problemas principalmente os relacionados à formação continuada do professor. A este respeito Paiva (2006) ainda revela que muitos professores simplesmente caíram em turmas de Educação de Jovens e Adultos com algum ou sem qualquer apoio para a realização das atividades relacionadas a esta modalidade de ensino. Adiciona-se a estes problemas a falta de ações práticas que garantam aos alunos um aprendizado significativo ao mesmo tempo em que aponte caminhos para um futuro profissional. 
Na contramão dos problemas da escola pública, um tipo de ação como a exposta neste relato possibilita a nós professores formarmos um conjunto de pessoas que passa a enxergar a arte a partir de outra ótica, a que se entrelaça com o mundo do trabalho, e que compreenda os processos mercadológicos que estão embutidos na produção que acaba tirando a arte da simples arte e a pondo no circuito comercial, acarretando às artesãs uma produção em grande escala o que se coaduna com o modelo de produção fordista em que para se dar conta das demandas, passa a existir uma linha de montagem na qual todo o trabalho é fragmentado e distribuído entre os trabalhadores que são responsáveis por apenas uma etapa de todo o processo.

Trata-se de um caráter mercadológico que vai fragmentando o trabalhador e vai retirando a arte de seu potencial libertador, fazendo com que o sujeito que a faz não aprecie esta arte e não a usufrua com prazer, mas a encare unicamente como um processo de alta produção e larga escala. Em contato com o contexto, essa é uma atividade que possibilita aos aprendizes compreender o processo histórico de transformação da arte em mercado, em fetiche, em mercadoria.

Esse tipo de ação, a partir da ótica pedagógica, é importante para ajudar os alunos da EJA a transcenderem o conhecimento das artes pelas artes, possibilita estes mesmos alunos a entenderem a questão de mercado, além de compreender o processo de precarização do artista quando este tem que produzir em larga escala. Entretanto, mesmo que parecido com o modelo fordista ${ }^{14}$, as diferenças de produção foram constadas nos núcleos de produção das artesãs (cinco no total, correspondente às cinco comunidades que compõe a Associação) que não ficam apenas com determinada etapa de todo o trabalho, pelo contrário, diante das demandas apenas dividem a quantidade de peças a serem criadas e cada artesã garante um trabalho final em que ela colheu, partiu, raspou, lixou, tingiu e riscou a cuia.

Ajuda também a entender como é que se dá o processo de trabalho. Como é que um artista, de posse da natureza, faz uso de seus braços, de suas pernas e de seu corpo para plasmar outra realidade que em si não era para o mercado, mas era para provocar sensibilidade.

Não obstante, essa posição pedagógica possibilitou ainda mais trabalhar as artes como elemento de identidade e trabalho a partir da relação do aprendiz com o mundo do trabalho artístico. Estar em sala de aula e apenas conhecer teoricamente o que se passa

\footnotetext{
${ }^{14}$ O Fordismo consistiu na substituição do processo artesanal de trabalho por uma linha de montagem na qual o trabalho passou a ser fragmentado. Modelo este de produção instituído por Henry Ford em sua indústria automobilística. Segundo Santos (2009, p. 2) "O fordismo se apoiou em cinco transformações, são elas: 1) produção em massa, 2) parcelamento das tarefas, 3) criação da linha de montagem, 4) padronização das peças, 5) automatização das fábricas."
}

Revista Digital do LAV - Santa Maria - vol. 8, n. 3, p. 48 - 72. - set./dez. $2015 \quad$ ISSN 1983 - 7348 http://dx.doi.org/10.5902/1983734820532 
no próprio ambiente de criação da arte é uma realidade muito presente no ensino das artes. Roriz (2010, p. 12) afirma que os "jovens podem ter interesse em qualquer um ofício artesanal, mas devidos aos obstáculos à concretização desse interesse em algo que thes gere uma renda satisfatória, acabam abrindo mão da produção cultural, para de dedicarem a outras atividades." A escola pode ter esse papel que media o ensino aliado a um contexto real, prática esta vivida pelos alunos da EJA em que presenciaram de perto o trabalho artístico e suas interfaces econômicas e culturais.

Não menos importante está o fato de termos conduzido os discentes da EJA a perceberem, a partir da experiência pedagógica aqui descrita, o trabalho realizado pelas artesãs enquanto produtor de cultura não decorrente de cursos realizados em ambientes formais de formação, mas uma produção resultante das experiências de trabalho por essas trabalhadoras desenvolvido. Ou seja, buscamos, a partir da inserção dos discentes da EJA nesse espaço de aprendizagem e de trabalho das artesãs dessa comunidade de Santarém, compreender que os homens, por meio do trabalho, produzem a existência e se formam, merecendo isso tudo reflexão por parte da escola, a partir do ensino das artes.

o projeto aqui desenvolvido considerou o enorme potencial da arte como elemento de transformação na vida da classe de jovens da EJA. Transformação em vários aspectos. Usou-se a arte como trampolim para perceber a realidade de outra plataforma e de forma mais crítica; consideramos as artes visuais como caminho possível para uma vida profissional; demonstramos que a arte, além de percebida e apreciada, relaciona-se com o trabalho e garante sustento; além de mostrar na prática que é possível relacionar teoria e prática dentro do contexto da educação de jovens e adultos.

\section{REFERÊNCIAS}

BECHARA, Evanildo. Dicionário da língua portuguesa Evanildo Bechara. Rio de Janeiro: Editora Nova Fronteira, 2011.

BRANDÃO, Carlos Rodrigues. A educação como cultura. Campinas, SP: Mercado de Letras, 2002.

BRASIL. Secretaria de Educação Fundamental. Parâmetros curriculares nacionais: arte/Secretaria de Educação Fundamental. Brasília: MEC, 1998. 116 p.

FARTHING, Stephen. Tudo sobre arte [tradução de Paolo Polzonof Jr. et al.]. Rio de Janeiro: Sextante, 2011.

FRANCO, Maria Laura P. B. Análise de conteúdo. Brasília: Líber Livro, 2007.

FRIGOTTO, Gaudêncio. Juventude, trabalho e educação no Brasil: perplexidades, desafios e perspectivas. In: NOVAES, Regina; VANNUCHI, Paulo (Orgs.). Juventude e Sociedade:

Revista Digital do LAV - Santa Maria - vol. 8, n. 3, p. 48 - 72. - set./dez. 2015 ISSN 1983 - 7348 http://dx.doi.org/10.5902/1983734820532 
trabalho, educação, cultura e participação. São Paulo: Editora Fundação Perseu Abramo, 2004.

JÚNIOR, Jeferson Oriente Brelaz Sampaio. Sinais distintivos para produtos de tradição cultural: registro da marca coletiva "aíra" para o artesanato de cuias em Santarém. In Terra, água, mulheres \& cuias: Aritapera, Santarém, Pará, Amazônia. SANTOS, Antônio Maria de Souza; CARVALHO, Luciana Gonçalves de. Organizadores. Belém: Prodetur, 2012, p. $72-84$.

LOPES, Alice Casimiro. Conhecimento escolar: ciência e cotidiano. Rio de Janeiro: EDUERJ, 1999.

MADURO, Rúbia Goreth Almeida. A cuia nossa de cada dia. In Terra, água, mulheres \& cuias: Aritapera, Santarém, Pará, Amazônia. SANTOS, Antônio Maria de Souza; CARVALHO, Luciana Gonçalves de. Organizadores. Belém: Prodetur, 2012, p. 31-38.

MARX, Karl. O Capital: crítica da economia política. Rio de Janeiro: Civilização Brasileira, 2008. V.1.

MICHELAT, Guy. Sobre a utilização da entrevista não diretiva em sociologia. In: THIOLLENT, Michel. Crítica metodológica, investigação social e enquete operária. São Paulo: Polis, 1985.

PAIVA, Jane. Histórico da EJA no Brasil: descontinuidades e políticas públicas insuficientes. In: EJA: formação técnica integrada ao ensino médio. Disponível em: http://portal.mec.gov.br/setec/arquivos/pdf2/boletim_salto16.pdf\#page=24. Acesso: 30.08.2015

PROENÇA, Graça. História da arte. Rio de Janeiro: Editora Ática, 2012.

RODRIGUES, Doriedson do Socorro. Saberes sociais e luta de classes: um estudo a partir da colônia de pescadores artesanais Z-16 - Cametá/Pará. Disponível em: http://www.ppged.belemvirtual.com.br/arquivos/File/tese_doriedson_pdf.pdf. Acesso em: 07.07.2015.

RORIZ, Priscilla Carvalho de oliveira. O Trabalho do artesão e suas interfaces culturaiseconômicas. Disponível em: http://repositorio.unb.br/bitstream/10482/7663/1/2010_PRISCILLACARVALHO.pdf. Acesso: 27.08.2015.

SANTOS, Vinicius Correa. Da era fordista ao desemprego estrutural da força do trabalho: mudanças na organização da produção e do trabalho e seus reflexos. Disponível em: http://www.ifch.unicamp.br/formulario_cemarx/selecao/2009/trabalhos/da-era-fordistaao-desemprego-estrutural-.pdf. Acesso: 01.09.2015.

SAVIANI, D. Painel sobre a Educação: VI Congresso da APP-Sindica. Foz do Iguaçu, 1995. SEMERARO, Giovanni. Gramsci e os novos embates da filosofia da práxis. São Paulo: Ideias \& Letras, 2006.

VÁZQUEZ, Adolfo Sánchez. Filosofia da Práxis. São Paulo: Expressão Popular, 2011. 
ZAIDAN, Samira. Saberes experienciais e saberes pedagógicos - um estudo. In: Revista Trabalho \& Educação (Núcleo de Estudos sobre Trabalho e Educação) - vol. 12, no 1 - jan / jun 2003. 